\title{
Brucella ovis EM OVINOS: SOROPOSITIVIDADE E FATORES DE RISCO
}

\author{
Brucella ovis IN SHEEP: SEROPOSITIVITY AND RISK FACTORS
}

\author{
Carlos Eduardo Dalencar Mendonça ${ }^{1}$ \\ Alexandre Dias Munhoz ${ }^{2}$ \\ Rodrigo Alves Bezerra ${ }^{2}$ \\ Luciana Afonso Guimarães ${ }^{2}$ \\ George Rego Albuquerque ${ }^{2}$ \\ Cristiano Barros de Melo ${ }^{1 *}$ \\ ${ }^{1}$ Universidade de Brasília, Brasília, DF, Brasil. \\ 2Universidade Estadual de Santa Cruz, Ilhéus, BA, Brasil \\ *Autor para correspondência - cristianomelo@unb.br
}

\section{Resumo}

Realizou-se um levantamento sorológico de Brucella ovis em ovinos do Estado de Sergipe, com o objetivo de determinar a positividade e a distribuição da infecção em propriedades rurais e analisar os possíveis fatores associados à infecção. Foram analisadas 54 propriedades criadoras de ovinos, das quais foram colhidas 932 amostras de soro sanguíneo de animais com idade superior a seis meses, nas três regiões do Estado. Todos os soros foram examinados por Imunodifusão em Gel de Agar (IDGA). De acordo com o teste realizado, 46,30\% (25/54) das propriedades apresentaram evidência sorológica de infecção por B. ovis, com uma positividade de 4,40\% (41/932) dos animais. Como fatores associados à infecção por $B$. ovis, observaram-se a presença de tratador de ovinos $(\mathrm{OR}=2,31)$ e propriedades com área superior a 50 ha $(\mathrm{OR}=1,98)$ e como fator de proteção, a utilização de cabanha $(\mathrm{OR}=0,37)$. Assim, verificou-se a presença de anticorpos contra Brucella ovis nos ovinos do Estado e salienta-se a importância de estudos complementares para determinação de medidas sanitárias específicas para prevenir os rebanhos desta enfermidade.

Palavras-chave: Brucelose; doença; epididimite ovina.

\begin{abstract}
Seroepidemiological study of Brucella ovis in sheep from Sergipe State was carried out to determine the seropositivity and infection distribution in rural properties and possible factors associated with infection. A total of 54 sheep properties were studied and 932 blood serum samples from animals older than six months were collected in the three regions of Sergipe State. All sera samples were examined by agar gel immunodiffusion (AGID). According to the serological tests, $46.30 \%$ (25/54) of the properties had serologic evidence of infection by B. ovis, with $4.40 \%$ of positive animals (41/932). Presence of sheep handler $(\mathrm{OR}=2.31)$ and properties with an area bigger
\end{abstract}


than 50 ha $(\mathrm{OR}=1.98)$ were observed as factors associated with $B$. ovis infection, whereas the use of stall $(\mathrm{OR}=0.37)$ worked as a protective factor $(\mathrm{OR}=0.40)$. Thus, the presence of antibodies against B. ovis in Sergipe State was confirmed, and it highlights the importance of complementary studies to determine the specific health measures in herds to prevent this disease.

Keywords: brucellosis; disease; sheep epididymitis.

Recebido em: 05 junho 2016

Aceito em: 29 setembro 2016

\section{Introdução}

Brucelose ovina é uma doença bacteriana infecciosa crônica causada por Brucella ovis e caracterizada por distúrbios reprodutivos, tais como diferentes graus de epididimite e orquite, placentite, aborto e elevada mortalidade de $\operatorname{cordeiros}^{(1-3)}$. Essa bactéria apresenta distribuição cosmopolita e seu primeiro relato foi realizado na Nova Zelândia ${ }^{(4)}$. No Brasil, o primeiro diagnóstico clínico da enfermidade causada por B. ovis foi relatado em $1966^{(5)}$ e o isolamento do agente em epidídimos de ovinos em $1972^{(6)}$, ambos no Estado do Rio Grande do Sul.

A Organização Mundial de Saúde Animal (OIE) recomendou a imunodifusão em gel de agar (IDGA) para diagnóstico sorológico da B. ovis com a utilização do extrato salino obtido por aquecimento a partir da cepa REO $198^{(7)}$. Este antígeno é rico em lipopolissacarídeo rugoso (LPSR) e outras proteínas externas de membrana ${ }^{(8)}$. A sensibilidade e especificidade da imunodifusão em gel de agar (IDGA) têm sido avaliadas por vários pesquisadores, sendo que a sensibilidade varia de $91,7 \%$ a $100 \%$ e a especificidade situa-se em torno de $100 \%{ }^{(9-11)}$.

Inquéritos sorológicos pontuais para B. ovis em ovinos têm sido efetuados no Brasil e os percentuais de reagentes encontrados variaram de 3,1\% no Estado de Alagoas $^{(12)}$ a $34 \%$ no Estado do Rio Grande do Norte ${ }^{(13)}$. Como fatores associados à infecção por $B$. Ovis, pode ser observado o tamanho do rebanho (rebanhos grandes), rebanhos sem lugares com água limpa, remoção de esterco insuficiente e limpeza inadequada de instalações, introdução de animais de rebanhos não-livres de bruceloses ou de rebanhos de status desconhecido ${ }^{(14)}$, aptidão produtiva ${ }^{(15)}$, compartilhamento de pastos com outros ruminantes ${ }^{(16,17)}$, empréstimo de ovinos durante estação reprodutiva, contato com outros rebanhos de ovinos ${ }^{(17)}$ e aquisição de animais e higiene anual das instalações ${ }^{(18)}$. Por outro lado, como fatores associados à proteção têm-se a frequente higiene das instalações ${ }^{(19)}$ e a idade dos criadores (mais velhos) ${ }^{(14)}$.

Considerando-se a importância econômica da pecuária ovina no Estado de Sergipe e a ausência de informações sobre a infecção desses animais por B. ovis, a realização do presente estudo teve por objetivo determinar a soropositividade de B. ovis em ovinos no Estado de Sergipe e detectar fatores associados à infecção. 


\section{Material e Métodos}

O estudo foi realizado na região Nordeste do Brasil, no Estado de Sergipe, o qual apresenta um rebanho ovino estimado de 247.703 animais, distribuídos em três mesorregiões: o Sertão, que possui 41,19\% dessa população; o Agreste, com 44,12\%; e o Leste, com 14,69\% (20). O rebanho ovino do Estado de Sergipe é composto basicamente por animais da raça Santa Inês, animais sem raça definida (SRD) e outras raças ${ }^{(20)}$.

Para a determinação do universo amostral, foram selecionados os municípios com maiores rebanhos ovinos de cada região do Estado, totalizando 19 municípios, sendo seis deles da mesorregião do Sertão (83.728 animais), seis do Agreste (89.688 animais) e sete do Leste (20.373), perfazendo 193.789 animais, que representam $78,23 \%$ da população ovina do Estado $^{(20)}$ (Figura 1).

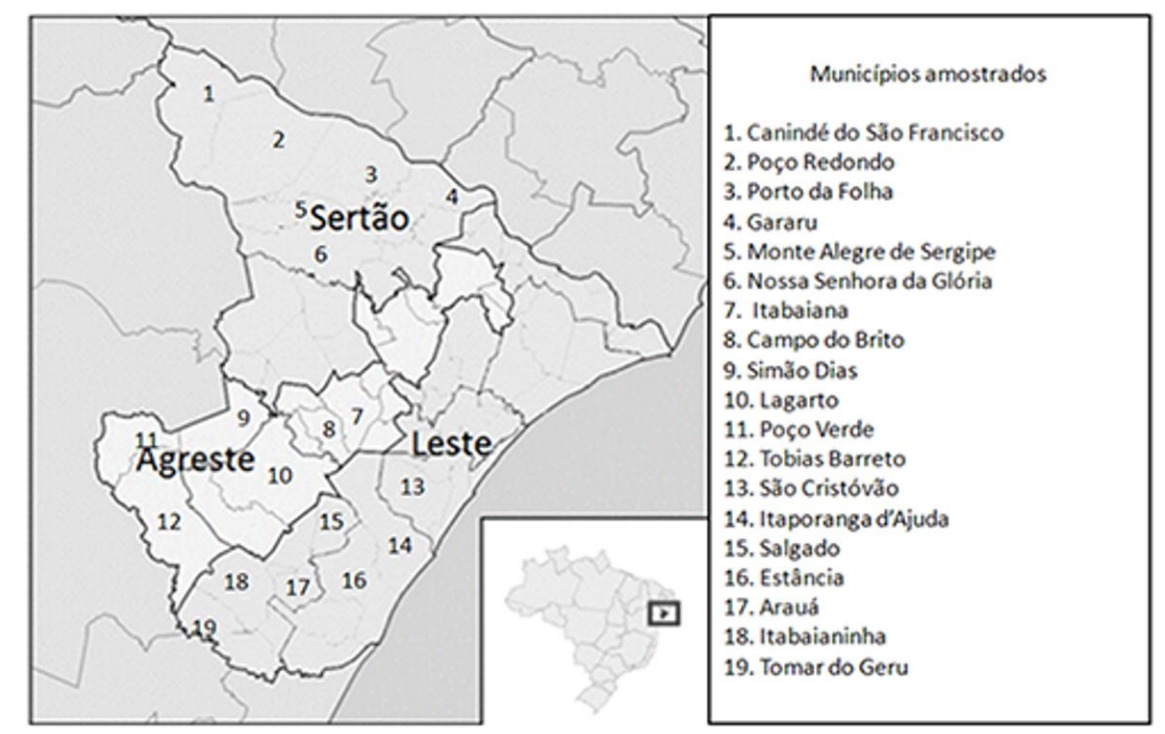

Figura 1. Mapa do Estado de Sergipe, dividido em mesorregiões (Sertão, Leste e Agreste), com os municípios onde as amostras foram coletadas.

O número mínimo de animais a serem amostrados (383) foi calculado pelo programa estatístico EPI-INFO versão $7^{(21)}$, considerando-se uma positividade esperada de $50 \%$, com erro amostral de $5 \%$ e grau de confiança de 95\%, para uma população de 193.789 animais. O número de propriedades a serem visitadas e amostras mínimas a serem colhidas por município foi determinado por proporcionalidade ao rebanho municipal.

A amostragem não probabilística foi utilizada para selecionar produtores e animais. Este foi o método de eleição por não existir uma listagem representativa dos produtores de ovinos no estado, o que tornou impossível um delineamento ao acaso. Foram colhidas 932 amostras oriundas de 54 propriedades, distribuídas nos 19 municípios, sendo 38,2\% (356/932) no Sertão, 44,85\% (418/932) no Agreste e 16,95\% (158/932) no Leste do Estado. 
A coleta das amostras ocorreu entre março e maio de 2008 e os métodos adotados foram aprovados pelo Comitê de Ética no Uso de Animais (protocolo-CEUA/UESC-39/2009). As amostras de sangue dos animais selecionados foram colhidas mediante punção da veia jugular externa. Estas foram centrifugadas a $1600 \mathrm{~g}$ por 10 minutos, sendo os soros separados, acondicionados em microtubos e congelados a $-20{ }^{\circ} \mathrm{C}$. Na oportunidade da visita, foi aplicada uma entrevista semiestruturada abordando dados do animal (sexo e idade), do criador (idade, atividade, tempo como criador), da propriedade (área, animais de produção presentes, origem da água), do sistema de produção (funcionários ligados à atividade, manejo produtivo, número de animais, tipo de reprodução, se realiza castração, instalações presentes), manejo sanitário (calendário de vacinação e vermifugação, histórico de doenças do rebanho, exames realizados, contato com outras espécies) e alimentar (administra sal mineral, silagem, feno).

Para a pesquisa de anticorpos contra $B$. ovis, foi utilizada a técnica de Imunodifusão em Gel de Ágar (IDGA) ${ }^{(30)}$, empregando-se kits comerciais produzidos pelo Instituto de Tecnologia do Paraná (TECPAR). A técnica foi executada de acordo com as instruções do fabricante, utilizando-se antígeno de lipopolissacarídeos e proteínas de B. ovis, amostra REO 198. A especificidade do teste é de $100 \%$ e a sensibilidade de $96,4 \%{ }^{(30)}$.

A leitura foi realizada após 48 e 72 horas, com luz indireta sobre fundo escuro, sendo considerada definitiva a última. Considerou-se como reação positiva a presença de uma linha de precipitação esbranquiçada e uniforme entre o poço teste e o antígeno, apresentando identidade com a linha formada pelo soro padrão; e como reação negativa a ausência de uma linha de precipitação ou sem linha de identidade ${ }^{(22)}$. As amostras de soro que tiveram resultados inconclusivos foram retestadas.

Para se identificarem os fatores de risco associados à infecção por B. ovis foi conduzida uma análise bivariada usando-se o teste qui-quadrado e o teste exato de Fisher com nível de significância a 5\%, utilizando-se o programa estatístico EPI-INFO versão $7^{(21)}$. Todas as variáveis com plausibilidade biológica e $\mathrm{p} \leq 0,2$ na análise bivariada foram submetidas a uma análise de colinearidade determinada pelo Teste de Spearman, no programa BioEstat 5.0 e, posteriormente uma análise de regressão logística multivariada não condicional (stepwise) foi executada no programa EPI-INFO.

\section{Resultados e Discussão}

Dos 932 soros examinados pelo teste de IDGA, 41 (4,40\%) foram positivos. Em relação aos municípios, 73,68\% (14/19) possuíam animais sororreagentes e 46,30\% (25/54) das propriedades apresentaram pelo menos um animal positivo para B. ovis no IDGA. Verificou-se alta positividade de rebanhos com baixa soropositividade de animais e esse resultado, do ponto de vista epidemiológico, sugere que a infecção seja endêmica ${ }^{(11)}$, pois regiões onde a enfermidade é recente há altas prevalências, de $20 \%$ a $60 \%$, enquanto regiões endêmicas tendem a apresentar prevalências menores.

Quando considerada a ocorrência por região, observaram-se 5,7\% de positivos no Leste (9/158), $3,35 \%$ no Agreste (14/418) e 5,06\% no Sertão (18/356). Não foi verificada diferença significativa 
entre as regiões. O município com maior número de amostras reagentes foi Tomar do Geru (4/21), enquanto o que apresentou menor frequência de positivos foi Canindé do São Francisco (1/49).

Comparando-se com os estudos realizados na região Nordeste, foram observados resultados mais elevados do que os obtidos no presente estudo, sendo $17,5 \%$ no Estado de Pernambuco ${ }^{(23)}$ e no Estado do Rio Grande do Norte foram observados índices de 34\% e 11,3\%(13,23), apesar de utilizarem mesma técnica o fator temporal.

Percentuais de reagentes relativamente semelhantes foram verificados no Estado da Paraíba ${ }^{(19)}$, com prevalência de 5,7\% (28/498) em reprodutores deslanados e 5,2\% (59/1134) de animais reagentes também na Paraíba ${ }^{(18)}$. No Estado de Alagoas foi observada positividade de $3,1 \%(18 / 579)^{(12)}$ e no Estado da Bahia foram verificados índices de 3,3\% (6/183) e 6,94\% $(30 / 793)^{(25,26)}$. Esses resultados indicam que os rebanhos da região estão sujeitos a condições semelhantes de exposição ao agente, sendo necessário o aprimoramento das práticas sanitárias aplicadas.

Em relação aos estudos conduzidos em outras regiões do país, observa-se que a positividade encontrada no Estado de Sergipe foi inferior à relatado para o Estado do Rio Grande do Sul $(13,4 \%)^{(26)}$; Estado de São Paulo $(12 \%)^{(27)}$ e Estado do Tocantins $(31,6 \%)^{(28)}$, o que pode ser justificado por diferenças regionais, condições de manejo, fatores espaciais e temporais.

Dos 41 animais positivos, apenas três eram machos reprodutores, pertencentes a propriedades distintas e únicos animais positivos do total amostrado em cada rebanho. Estas propriedades apresentaram histórico de abortamento, apesar de não terem sido encontradas fêmeas positivas na amostra.

$\mathrm{Na}$ análise bivariada (Tabela 1), verificaram-se como variáveis com plausibilidade biológica, p-valor $\leq 0,2$ e correlação $\mathrm{p} \leq 0,8$, a presença de tratador de ovinos, a realização de exame de brucelose, a presença de águas limpas, a utilização de cabanha, a realização de castração e a apresentação de propriedade com área superior a 50 hectares. No modelo final, permaneceu como fator associado à infecção por Brucella ovis apresentar tratador de ovinos e ter propriedade com área superior a 50 ha, e como fator associado à proteção, utilizar cabanha (Tabela 2).

As variáveis "realizar castração" (P-valor=0,0892) e "realizar exame de Brucella ovis" (P-valor= 0,0747), apontadas como fatores de proteção, não permaneceram no modelo final da regressão logística, mas houve tendência à proteção segundo análise bivariada. Esses resultados são justificáveis, pois a castração reduz o número de machos sexualmente ativos, reduzindo o número de parceiros sexuais e, consequentemente, mitigando o risco de transmissão venérea ${ }^{(8)}$, enquanto a realização de exame de $B$. ovis permite a adoção do descarte orientado e reduz o risco de introdução de animais infectados ${ }^{(14,18,19)}$.

Observou-se que a área da propriedade, quando superior a 50 hectares, foi um fator associado à infecção (OR = 1,98). Porém, esse resultado deve ser analisado com cautela, pois o tamanho da propriedade não representa a área de pastejo dos animais, uma vez que nas criações estudadas notou-se maior tecnificação com área de pastejo limitada em propriedades mais extensas, não sendo possível associar o tamanho da fazenda com sistema de pastejo extensivo ${ }^{(12)}$.

A variável "ter tratador de ovinos" se comportou como fator de risco $(\mathrm{OR}=2,31)$. Condições de manejo que favorecem a aglomeração dos animais podem contribuir para a disseminação de 
doenças infecto-contagiosas no rebanho, quando um ou mais animais infectados estão presentes ${ }^{(31)}$, e a presença do tratador de ovinos reflete a maior intensidade de manejo dos animais, aumentando o contato entre estes e potencializando o risco de infecção. Ainda é possível que o homem atue como vetor mecânico da bactéria, aumentando as chances de infecção ${ }^{(19)}$.

Tabela 1. Análise bivariada entre variáveis e presença de anticorpos contra Brucella ovis em ovinos do Estado de Sergipe

\begin{tabular}{|c|c|c|c|c|c|}
\hline \multirow[t]{2}{*}{ Variảveis } & \multicolumn{2}{|c|}{$\begin{array}{l}\text { Ovinos } \\
\text { Positivos }\end{array}$} & \multicolumn{2}{|c|}{$\begin{array}{c}\text { Ovinos } \\
\text { Negativos }\end{array}$} & \multirow[t]{2}{*}{ P.Valor } \\
\hline & $\mathrm{n}$ & $\%$ & $\mathrm{n}$ & $\%$ & \\
\hline \multicolumn{6}{|l|}{ Idade } \\
\hline$<1$ ano & 13 & 4,4 & 285 & 95,6 & \\
\hline Entre 1 e 3 anos & 13 & 4,3 & 290 & 95,7 & \\
\hline$>3$ anos & 15 & 4,5 & 316 & 95,5 & 0,9884 \\
\hline \multicolumn{6}{|c|}{ Consomem água de poço profundo } \\
\hline Sim & 3 & 3,8 & 75 & 96,2 & \\
\hline Não & 38 & 4,4 & $\$ 16$ & 95,6 & $0,5456^{F}$ \\
\hline \multicolumn{6}{|l|}{ Cria caprinos } \\
\hline $\operatorname{Sim}$ & 3 & 2,4 & 121 & 97,5 & \\
\hline Não & 38 & 4,7 & 770 & 95,3 & $0,3579^{F}$ \\
\hline \multicolumn{6}{|l|}{ Empréstimo de reprodutores } \\
\hline $\operatorname{Sim}$ & $s$ & 5,1 & 149 & 94,9 & \\
\hline Nào & 33 & 4,3 & 742 & 95,7 & 0,8000 \\
\hline \multicolumn{6}{|l|}{ Utiliza cabanha } \\
\hline $\operatorname{Sim}$ & 25 & 3,7 & 655 & 96,35 & \\
\hline Não & 16 & 6,3 & 236 & 93,65 & 0,0772 \\
\hline \multicolumn{6}{|l|}{ Consomem água de cisterna } \\
\hline Sim & 0 & 0 & 42 & 57,1 & \\
\hline Não & 41 & 100 & 849 & 72,4 & $0,1447^{F}$ \\
\hline \multicolumn{6}{|l|}{ Presença de águas limpas } \\
\hline Sim & 38 & 5,0 & 716 & 95,0 & \\
\hline Não & 3 & 1,7 & 175 & 98,3 & $0,0785^{F}$ \\
\hline \multicolumn{6}{|l|}{ Sexo } \\
\hline Macho & $s$ & 4,2 & 184 & 95,8 & \\
\hline Fèmea & 33 & 4,5 & 707 & 95,5 & 0,9830 \\
\hline \multicolumn{6}{|l|}{ Realiza exame (Brucella ovis) } \\
\hline Sim & 7 & $\$, 1$ & 79 & 91,9 & \\
\hline Não & 34 & 4,0 & $\$ 12$ & 96,0 & $0,0747^{F}$ \\
\hline \multicolumn{6}{|l|}{ Realiza castração } \\
\hline Sim & 12 & 3 & 392 & 97,0 & \\
\hline Não & 29 & 5,5 & 499 & 94,5 & $0,0 \$ 92$ \\
\hline \multicolumn{6}{|l|}{ Area maior que 50 ha } \\
\hline $\operatorname{Sim}$ & 23 & 6,4 & 336 & 95,6 & 0,0180 \\
\hline Não & 18 & 3,1 & 555 & 96,9 & \\
\hline \multicolumn{6}{|l|}{ Cria há mais de 10 anos } \\
\hline Sim & 18 & 4,9 & 352 & 95,1 & \\
\hline Não & 23 & 4,1 & 539 & 95,9 & 0,6897 \\
\hline \multicolumn{6}{|l|}{ Manejo reprodutivo } \\
\hline Monta natural & 11 & 5,24 & 199 & 94,76 & $0,6074^{F}$ \\
\hline Monta controlada & 30 & 4,23 & 679 & 95,77 & \\
\hline \multirow{2}{*}{\multicolumn{6}{|c|}{ Possui tratador de ovinos }} \\
\hline & & & & & \\
\hline Sim & 22 & 6,0 & 343 & 94,0 & \\
\hline Não & 19 & 3,4 & 548 & 96,6 & 0,0759 \\
\hline \multicolumn{6}{|l|}{ Mais de 100 animais } \\
\hline $\operatorname{Sim}$ & 21 & 5,0 & 401 & 95,0 & \\
\hline Năo & 20 & 3,9 & 490 & 96,1 & 0,5345 \\
\hline \multicolumn{6}{|l|}{ Sistema de manejo } \\
\hline Extensivo & 13 & 4,71 & 263 & 95,29 & $0,8527^{\mathrm{F}}$ \\
\hline Semi-intensivo & 27 & 4,36 & 592 & 95,64 & \\
\hline Intensivo & 1 & 2,70 & 36 & 97,30 & \\
\hline
\end{tabular}

${ }^{\text {F }}$ Teste exato de Fisher. 
Tabela 2. Modelo final da regressão logística não-condicional dos fatores associados à infecção sorológica de Brucella ovis em ovinos no Estado de Sergipe, Nordeste do Brasil

\begin{tabular}{lccc}
\hline Variável & Odds Ratio & IC (95\%) & P-valor \\
\hline Ter tratador de ovinos & 2,3067 & $1,13-4,71$ & 0,0219 \\
A resentar área maior que 50 ha & 1,9776 & $1,03-3,80$ & 0,0404 \\
Utilizar cabanha & 0,3662 & $0,18-0,75$ & 0,0064 \\
\hline
\end{tabular}

$P$-valor $=0,0021, \log$-likelihood $=321,5977$

O uso de cabanha nas propriedades se apresentou como fator de proteção $(\mathrm{OR}=0,37)$, oposto ao já verificado na literatura ${ }^{(26)}$. Possivelmente isso ocorreu devido à prática de retirada das fezes para utilização como adubo nas próprias terras ou para comercialização, recolhendo-as regularmente. Neste estudo, a variável "frequência de higienização das instalações" não foi avaliada, porém pesquisas anteriores indicaram que a baixa frequência de higienização (anual) aumenta a chance de infecção pela bactéria ${ }^{(18)}$.

Em relação ao teste sorológico utilizado, a Imunodifusão em Gel de Ágar (IDGA) é considerado o teste mais prático em laboratórios não especializados; entretanto, a Organização Mundial de Saúde Animal (OIE) também indica a realização do Teste de Fixação de Complemento (TFC) e o ELISA Indireto. Além disso, considerando-se a falta de padronização internacional para os testes de IDGA e ELISA Indireto, o TFC é o teste prescrito para o comércio internacional. Métodos diretos para diagnóstico são realizados com base no isolamento bacteriológico de B. ovis de amostras de sêmen ou tecidos de carneiros, ou descargas vaginais, leite e tecidos de ovelhas, em meios seletivos adequados, bem como métodos moleculares têm sido desenvolvidos para a identificação complementar, como a Reação em Cadeia da Polimerase (PCR) ${ }^{(32)}$.

É importante que seja realizado o controle dessa infecção, uma vez que gera grandes perdas produtivas $^{(10)}$, ainda que os animais não apresentem sinais clínicos ${ }^{(29)}$, interferindo severamente no status sanitário do rebanho, especialmente por apresentar morbidade significativa ${ }^{(7)}$.

\section{Conclusão}

Foi constatada a presença de ovinos sorologicamente positivos para Brucella ovis em rebanhos de Sergipe, com grande proporção de propriedades com pelo menos um animal soropositivo. São necessários estudos complementares para a elucidação da epidemiologia da $B$. ovis e implantação de medidas de controle adequadas, além da conscientização dos criadores, através de programas de educação sanitária para prevenir e erradicar à doença de suas propriedades.

\section{Agradecimentos}

Ao CNPq e à CAPES. 


\section{Referências}

1. Niilo L, Macdonald DW, Godkin GF \& Stone MW. Ovine brucellosis in Alberta. Can. Vet. J., 1986, 27 : 245-249

2. Homse AC, Casaro AP \&Campero CM. Infertilidad em ovejas por Brucella ovis. Vet. Arg., 1995, 12:243249.

3. Baigún R, Conigliaro AS \& Luna F. Aislamiento de Brucella ovis y control de reaccionantes serológicos en epididimitis ovina. Vet. Arg., 2000, 17:103-107.

4. Buddle MB \& Boyes BW. A Brucella mutant causing genital disease of sheep in New Zealand. Aust. Vet. J., 1953, 29:145-153.

5. Ramos AA, Mies Filhos A, Schenck JAP, Vasconcellos LD, Prado OTG, Fernandes JCT \& Blobel H. Epididimite ovina, levantamento clínico no Rio Grande do Sul. Pesq. Agropec. Bras., 1966, 1: 211-213.

6. Blobel H, Fernandes JCT, Mies Filho A, Ramos AA \& Trein EJ. Estudos sobre a etiologia da epididimite ovina no Rio Grande do Sul. Pesq. Vet. Bras., 1972, 7:1-4.

7. OIE - Word Animal Health Association. http://www.oie.int/wahis/public/country population> 2011.

8. Estein SM. Aspectos inmunológicos en el diagnóstico y control de La epididimitis contagiosa del carnero por Brucella ovis. Arch. Med. Vet. 1999, 31:5-17.

9. Worthington RW, Weddell W \& Penrose ME. A comparison of three serological tests for the diagnosis of Brucella ovis infection in rams. N. Z. Vet. J., 1984, 32:58-60.

10. Ficapal A, Jordana J, Blasco JM \& Moriyón I. Diagnosis and epidemiology of Brucella ovis infection in rams. Sm. Rum. Res., 1998, 29:13-19.

11. Robles CA. Epididimite contagiosa de los carneros por Brucella ovis. Rev. Med. Vet., 1998, 79:67-71.

12. Pinheiro Junior JW, Oliveira AAF, Mota RA, Agottani JV, Jesus EM, Assis ST \& Oliveira CZ. Ocorrência de ovinos sororeatores para Brucella ovis no Estado de Alagoas, Brasil. Vet. Zootec., 2009, 16(3): 500-508.

13. Silva JBA, Feijó FMC, Teixeira MFS \& Silva JS. Prevalência de brucelose ovina causada por Brucella ovis em rebanhos do Estado do Rio Grande do Norte, Brasil. Ciênc. Anim. Bras., 2003, 13:51-54.

14. Coelho AM, Coelho AC, Roboredo M \& Rodrigues J. A case-control study of risk factors for brucellosis seropositivity in Portuguese small ruminants herds. Prev. Vet. Med., 2007, 82:291-301.

15. Coelho AM, Coelho AC, Góis J, Pinto ML \& Rodrigues J. Multifactorial correspondence analysis of risk factors for sheep and goat brucellosis seroprevalence. Sm. Rum. Res., 2008, 78:181-185.

16. Riviriego FJ, Moreno MA \& Domínguez L. Risk factors for brucellosis seroprevalence of sheep and goat flocks in Spain. Prev. Vet. Res., 2000, 44:167-173.

17. Al-Majali AM, Majok AA, Amarin NM \& Al-Rawashdeh OF. Prevalence of, and risk factors for, brucellosis in Awassi sheep in Southern Jordan. Small Rum. Res., 2007, 73:300-303.

18 Santos FA, Higino SSS, Azevedo SS, Costa DF, Farias AEM, Alves FAL, Paulin LM \& Alves CJ. Caracterização epidemiológica e fatores de risco associados à infecção por Brucella ovis em ovinos deslanados do semiárido paraibano. Pesq. Vet. Bras., 2013, 33(4): 459-463.

19. Clementino IJ, Alves CJ, Azevedo SS, Paulin LM \& Medeiros KA. Inquérito soroepidemiológico e 
fatores de risco associados à infecção por Brucella ovis em carneiros deslanados do semi-árido da Paraíba. Pesq. Vet. Bras., 2007, 27:137-143.

20. Governo de Sergipe. Secretaria do Estado da Agricultura e do Desenvolvimento Agrário, Aracaju. 2011. Disponível em http://www.sagri.se.gov.br/modules/tinyd0/index.php?id=49 Acesso em jan. 2011.

21. CDC - Centers for Disease Control and Prevention, 1600 Clifton Road Atlanta, GA 30329-4027, USA, 800-CDC-INFO, 2010. https://www.cdc.gov/cdc-info.

22. Azevedo SS, Alves CJ, Batista CSA, Clementino IJ, Santos FA \& Alves FAL. Ocorrência de anticorpos anti-Brucella ovis em ovinos procedentes de quatro municípios do estado do Rio Grande do Norte, Brasil. Agrop. Téc. 2004, 25(2): 45-50.

23. Coleto ZF, Pinheiro Júnior JW, Mota RA, Guerra MMP, Simplício KMMG, Câmara DR, Soares RPT, Porto WJN, Cintra Júnior, J, Faustino MAG, Souza AF \& Berto RS. Ocorrência de infecção por Brucella ovis em ovinos do Estado de Pernambuco e sua participação em distúrbios reprodutivos nesta espécie. Rev. Bras. Reprod. Anim., 2003, 27:551-553.

24. Silva NS, Barros IN, Dasso MG, Almeida MGAR, Laborda SS, Anunciação AVM, Moreira ELT, LimaSilva AL \& Oliveira EMD. Detecção de anticorpos anti-Brucella ovis em ovinos do estado da Bahia. Rev. Bras. Saúde Prod. Anim., 2009, 10:852-859.

25. Araujo BR, Costa JN, Souza TS, Lima CCV, Leite, MDX, Costa Neto AO, Anunciação AVM, Almeida AGAR \& Lima EB. Seroepidemiology of sheep brucellosis in the microregion of Feira de Santana, BA, Brazil. Braz. J. Vet. Res. Anim. Sci., 2013, 50(2): 129-135.

26. Magalhães Neto A \& Gil-Turnes C. Brucelose ovina no Rio Grande do Sul. Pesq. Vet. Bras. 1996, 16:7579.

27. Nozaki CN, Megid KC, Silva Junior FF \& Veloso CS. Comparação das técnicas de imunodifusão em gel de ágar e ELISA no diagnóstico de brucelose ovina em cabanhas da região Centro-Oeste do Estado de São Paulo. Arq. Inst. Biol., 2004, 71 (1):1-5.

28. Martins NEX, Almeida JDM Silva MG, Sousa MG, Mathias LA \& Almeida KA. Prevalência de anticorpos anti-Brucella ovis e anti-Brucella abortus em ovinos do município de Colinas, Tocantins, Brasil. Rev. Patol. Trop., 2013, 42(2): 147-160.

29. Carvalho Junior CA, Moustacas VS, Xavier MN, Costa EA, Costa LF, Silva TMA, Paixão TA, Borges AM, Gouveia AMG. \& Santos RL. Andrological, pathologic, morphometric, and ultrasonographic findings in rams experimentally infectes with Brucella ovis. Small. Rum. Res., 2012, 102:213-222.

30. Tecpar - Instituto de Tecnologia do Paraná. Antígeno para diagnóstico de Brucella ovis. http://portal.tecpar.br/wp-content/uploads/2014/11/Brucella-OVIS-2013.pdf

31. Radostits OM, Gay CC, Blood DC \& Hinchcliff KW. Clínica Veterinária: um tratado de doenças dos bovinos, ovinos, suínos, caprinos e eqüinos. $9^{\mathrm{a}}$ ed. Guanabara Koogan, Rio de Janeiro. 2002, 1737p.

32. World Organisation for Animal Health (OIE). Terrestrial Manual, Chapter 2.7.8 - Ovine Epididymitis (Brucella ovis),

2015 . http://www.oie.int/fileadmin/Home/eng/Health_standards/tahm/2.07.08_OVINE_EPID.pdf 